\title{
Advances in the development of new biologics in inflammatory bowel disease
}

\author{
Bella Ungar, Uri Kopylov
}

Sheba Medical Center, Tel Hashomer and Sackler Faculty of Medicine, Tel Aviv University, Israel

\begin{abstract}
Biologics have revolutionized the therapeutic approach in inflammatory bowel disease (IBD). Anti-tumor necrosis factor (anti-TNF) agents infliximab and adalimumab currently constitute the major biological therapy in IBD. Additional anti-TNFs such as golimumab and other new biologics are currently being developed for both anti-TNF-naïve and -resistant patients. These include anti-integrins (vedolizumab and etrolizumab), a JAK inhibitor (tofacitinib) and an anti-anti-interleukin (IL)-23 and IL-12 antibody (ustekinumab), among additional drugs in development. The following review discusses the indications, efficacy and safety issues for these novel medications.
\end{abstract}

Keywords Inflammatory bowel disease, Crohn's disease, ulcerative colitis, therapy, biologics

Ann Gastroenterol 2016; 29 (3): 1-6

\section{Introduction}

During the last 15 years, the main progress in the field of inflammatory bowel disease (IBD) therapy has been related to development of anti-tumor necrosis factor (anti-TNF) agents. However, approximately $20 \%$ of patients do not respond to anti-TNFs, and over $30 \%$ eventually lose response $[1,2]$. In addition, these drugs have been shown to increase the risk of infections and malignancies $[3,4]$. These, together with improved comprehension of biological pathways involved in the pathogenesis of the inflammatory process in IBD, have led to the development of several new biological medications for Crohn's disease (CD) and ulcerative colitis (UC). A summary of the clinical data pertaining to the therapeutic agents discussed in this review is presented in Tables 1 and 2 .

Department of Gastroenterology, Sheba Medical Center, Tel Hashomer, and Sackler Faculty of Medicine, Tel Aviv University, Israel

Conflict of Interest: Uri Kopylov: Lecture fees from Abbvie, Janssen, Takeda, CTS, consulting fees from Janssen

Correspondence to: Uri Kopylov, Department of Gastroenterology, Sheba Medical Center, Tel Hashomer, and Sackler Faculty of Medicine, Tel Aviv University, Ramat Gan 52621 Israel, Tel.: +972 35302660 , Fax:+972 3 5303160, e-mail: ukopylov@gmail.com

Received 31 December 2015; accepted 22 February 2016 Published online 24 March 2016

DOI: http://dx.doi.org/10.20524/aog.2016.0027

\section{Anti-TNF-a}

Infliximab and adalimumab are considered the mainstay of biological therapy in IBD for the last decade. They have been shown to induce clinical and endoscopic remission in both CD and UC, to diminish exacerbations and surgery rates [5-9]. Certolizumab is a pegylated monoclonal IgG antibody against TNF- $\alpha$. It was approved by the Food and Drug Administration (FDA) at 2008 for both induction and maintenance of remission in moderately-to-severely active $\mathrm{CD}$, including patients who have previously lost response to infliximab [10,11-13]. It has been shown that lower drug levels and existence of antidrug antibodies correlate with loss of clinical and endoscopic response.

\section{Golimumab}

Golimumab, a human monoclonal IgG1 antibody against TNF, was recently approved for moderately-to-severely active UC [14]. The main studies which evaluated golimumab efficacy and safety are the PURSUIT I and II trials. PURSUIT I demonstrated that at week 6 , more patients with active UC in the golimumab $200 / 100 \mathrm{mg}$ and $400 / 200 \mathrm{mg}$ groups (51.0\%, and $54.9 \%$ respectively) responded compared with patients who received placebo ( $30.3 \%$; $\mathrm{P}<0.0001$ for both comparisons). Mucosal healing was achieved in $42.3 \%$ and $45.1 \%$ in the golimumab therapy groups vs. $28.7 \%$ in the placebo group $(\mathrm{P}=0.0014$ and $\mathrm{P}<0.001$ for the $200 / 100 \mathrm{mg}$ and $400 / 200 \mathrm{mg}$ dosages, respectively). No significant difference in adverse events was detected [15]. 
PURSUIT II evaluated golimumab maintenance therapy. The proportion of patients who maintained response to therapy until week 54 was higher in the $100-\mathrm{mg}$ and $50-\mathrm{mg}$ groups (49.7\% and $47.0 \%$, respectively) compared with patients who received placebo (31.2\%; $\mathrm{P}<0.001$ and $\mathrm{P}<0.01$, respectively). Mucosal healing at weeks 30 and 54 was significantly greater for patients receiving golimumab $100 \mathrm{mg}$ (42.4\%) compared with placebo (26.6\%; $\mathrm{P}=0.002)$. Efficacy in patients who received both intra-venous (IV) and sub-cutaneous (SC) induction therapy was similar [16].

PURSUIT IV specifically compared IV and SC golimumab therapy. Efficacy with single-dose golimumab IV induction was lower than that demonstrated in the SC induction study. At each corresponding IV and SC dose level (i.e. $1 \mathrm{mg} / \mathrm{kg}$ - 100/50 mg, $2 \mathrm{mg} / \mathrm{kg}$ - 200/100 mg and $4 \mathrm{mg} / \mathrm{kg}$ - 400/200 mg), serum golimumab concentrations for the SC dose were higher than those for the IV dose at weeks 2, 4 and 6 [17].

Adverse effects in the golimumab treatment groups are similar to those observed with other anti-TNFs, mainly severe infections. Data regarding combination therapy with an immunomodulator, effect of prior anti-TNF therapy, as well as complex disease phenotype are lacking [18].

\section{Immunogenicity}

$3 / 721$ patients $(0.4 \%)$ who had available sera samples, treated with golimumab at the PURSUIT I trial, were positive for antibodies to golimumab. Incidence of antibodies to golimumab until week 54 was $2.9 \%$ (32 out of 1103 patients) in the PURSUIT II study. Rate of antibody formation to golimumab among those who received concomitant immunomodulators was lower $[1.1 \%$ (4 of 362)] compared with patients who were not receiving concomitant immunomodulators $(3.8 \%, 28$ of 741, $\mathrm{P}=0.013$ ). These findings are in accordance with the rheumatological studies, which suggested that monotherapy was associated with a higher rate of antibody formation [19]. A recent study showed that the proportion of antibody positivity $(15.2 \%, 5 / 33)$ in patients with rheumatoid arthritis (RA) was higher than in other studies $(2.1 \%-8.1 \%)$. In ankylosing spondylitis, antibodies were detectable in only one $(2.3 \%)$ patient, consistent with previous findings that $4.1 \%$ of patients with ankylosing spondylitis developed immunogenicity [20].

In summary, the PURSUIT trials have demonstrated that golimumab is effective for induction and maintenance of clinical and endoscopic remission in anti-TNF naïve UC patients. SC administration has been shown to be more effective than single IV dosage.

\section{Integrin antagonists}

These are antibodies which target the leukocyte adhesion and trafficking, thereby reducing inflammation. Integrin antagonists have recently shown promising results in induction and maintenance of remission for both CD and UC patients [21].

\section{Natalizumab}

Natalizumab blocks the a4 integrin on lymphocytes, which takes part in constituting the immune response in the central nervous system and the gut. Natalizumab induced and maintained remission in patients with moderate-to-severe $\mathrm{CD}$ [22], but was found to increase the risk of progressive multifocal leukoencephalopathy (PML, approx. 1/300 patients), a central nervous system JC virus infection that can be lethal due to impaired central nervous system immune function. Antibodies to JC virus, use of concomitant immunosuppressives and increased duration of natalizumab treatment have been shown to increase PML risk [23]. Natalizumab was temporarily withdrawn from the market but was reintroduced in 2006 in the USA using a surveillance program [24].

\section{Vedolizumab}

Vedolizumab is a humanized monoclonal antibody that recognizes the gut-specific $\alpha 4 \beta 7$ subunit. It has been approved in moderate-to-severe UC or CD. GEMINI I trial demonstrated that vedolizumab is effective and safe for induction and maintenance in moderate-to-severe UC. At week 6, 47.1\% $(106 / 225)$ patients who received vedolizumab vs. $25.5 \%$ $(38 / 149)$ patients who received placebo had a clinical response $(\mathrm{P}<0.001) .38$ patients receiving vedolizumab $(16.9 \%)$ and 8 receiving placebo $(5.4 \%)$ had clinical remission $(\mathrm{P}=0.001)$. Rates of mucosal healing were $40.9 \%$ ( $92 / 225$ patients) with vedolizumab and $24.8 \%(37 / 149)$ with placebo $(\mathrm{P}=0.001)$. At week 52, patients who continued receiving the drug were more likely to achieve clinical remission than were those randomly assigned to switch to placebo $(41.8 \%, 44.8 \%$ for vedolizumab every 8 and 4 weeks vs. $15.9 \%$ placebo patients). No clear differences in efficacy were observed between the two vedolizumab regimens (every 8 or 4 weeks). Concomitant glucocorticoids or immunomodulators or previous therapy with anti-TNFs did not substantively affect outcome [25]. No significant differences were observed among the study groups in the rates of adverse events. No cases of PML occurred [26].

A network meta-analysis showed that in patients with moderate-to-severe UC, naïve to biologics, vedolizumab has similar efficacy to infliximab, adalimumab and golimumab, for induction and maintenance. Only vedolizumab had a lower incidence of serious adverse events compared with placebo [26,27].

GEMINI II trial evaluated vedolizumab therapy among CD patients. Vedolizumab-treated active CD patients were more likely than patients receiving placebo to undergo clinical remission at week $6(32 / 220,14.5 \%$ vs. $10 / 148,6.8 \%, \mathrm{P}=0.02)$, but not a CD activity index (CDAI)-100 response $(\mathrm{P}=0.23)$. At week 52,60/154 patients (39.0\%) treated with vedolizumab every 8 weeks and 56/154 patients $(36.4 \%)$ on vedolizumab every 4 weeks were in clinical remission, compared with $33 / 153$ patients $(21.6 \%)$ under placebo $(\mathrm{P}<0.001$ and $\mathrm{P}=0.004$ respectively). Serious infections were identified in $5.5 \%$ of vedolizumab therapy patients compared with $3.0 \%$ of the 
Table 1 Comparison of the major biologics currently available or under final development

\begin{tabular}{|c|c|c|c|c|c|c|}
\hline Drug & Certolizumab & Golimumab & Vedolizumab & Etrolizumab & Ustekinumab & Tofacitinib \\
\hline $\mathrm{CD} / \mathrm{UC}$ & $\mathrm{CD}$ & $\mathrm{UC}$ & $\mathrm{CD} \& \mathrm{UC}$ & UC & $\mathrm{CD}$ & $\mathrm{CD} \& \mathrm{UC}$ \\
\hline $\begin{array}{l}\text { Response in } \\
\text { complicated CD }\end{array}$ & + & - & No data & - & Limited data & Limited data \\
\hline $\begin{array}{l}\text { Combination } \\
\text { therapy }\end{array}$ & No data & No data & $\begin{array}{l}\text { Did not increase } \\
\text { efficacy }\end{array}$ & $\begin{array}{l}\text { Increased rate } \\
\text { of remission }\end{array}$ & No data & No data \\
\hline $\begin{array}{l}\text { Immunogenicity } \\
\text { rate }(\%)\end{array}$ & $4-8$ & $0.4-2.9$ & $\begin{array}{l}3.7 \text { (UC), } \\
4.1(\mathrm{CD})\end{array}$ & 5 & 0.7 & No data \\
\hline Mucosal healing & Limited data & + & + & Limited data & $\begin{array}{l}\text { - , but small } \\
\text { sample size }\end{array}$ & \\
\hline $\begin{array}{l}\text { Response after } \\
\text { anti-TNF failure }\end{array}$ & + & Limited data & + & Limited data & + & \\
\hline Adverse events & $\begin{array}{l}\text { Similar to previous } \\
\text { anti-TNFs }\end{array}$ & $\begin{array}{l}\text { Similar to previous } \\
\text { anti-TNFs }\end{array}$ & $\begin{array}{l}\text { Similar to } \\
\text { placebo }\end{array}$ & $\begin{array}{l}\text { Similar to } \\
\text { placebo }\end{array}$ & $\begin{array}{l}\text { Similar to previous } \\
\text { anti-TNFs, but one } \\
\text { case of PML }\end{array}$ & $\begin{array}{l}\text { Similar to } \\
\text { anti-TNFs }\end{array}$ \\
\hline $\begin{array}{l}\text { Other approved } \\
\text { indications }\end{array}$ & $\begin{array}{l}\mathrm{CD} \text {, Rheumatoid } \\
\text { and psoriatic } \\
\text { arthritis }\end{array}$ & $\begin{array}{l}\text { UC, rheumatoid } \\
\text { arthritis, psoriatic arthritis, } \\
\text { ankylosing spondylitis }\end{array}$ & $\mathrm{UC}, \mathrm{CD}$ & - & $\begin{array}{l}\text { Psoriasis and } \\
\text { psoriatic arthritis }\end{array}$ & $\begin{array}{l}\text { Rheumatoid } \\
\text { arthritis }\end{array}$ \\
\hline
\end{tabular}

Table 2 Pivotal studies for the major current biological therapies for $\mathrm{CD}$ and UC

\begin{tabular}{|c|c|c|}
\hline Drug & Pivotal studies & Summary \\
\hline \multirow[t]{3}{*}{ Golimumab } & PURSUIT I & Induction in UC \\
\hline & PURSUIT II & Maintenance in UC \\
\hline & PURSUIT IV & IV versus SC \\
\hline \multirow[t]{2}{*}{ Vedolizumab } & GEMINI I & $\begin{array}{l}\text { Induction and } \\
\text { maintenance in UC }\end{array}$ \\
\hline & GEMINI II & $\begin{array}{l}\text { Induction and } \\
\text { maintenance in } \mathrm{CD}\end{array}$ \\
\hline Etrolizumab & Etrolizumab phase II & Induction in UC \\
\hline \multirow[t]{3}{*}{ Ustekinumab } & CERTIFI (phase IIb) & $\begin{array}{l}\text { Induction and maintenance } \\
\text { in refractory } C D\end{array}$ \\
\hline & UNITI I (phase 3) & Induction in refractory CD \\
\hline & $\begin{array}{l}\text { UNITI II (phase 3) - } \\
\text { underway }\end{array}$ & $\begin{array}{l}\text { Maintenance in } \\
\text { refractory CD }\end{array}$ \\
\hline
\end{tabular}

patients under placebo. No cases of PML or malignancies were identified [28-31].

Since the GEMINI trials, several cohort studies have followed UC and CD vedolizumab therapy patients and have shown a favorable profile of efficacy and limited adverse events. Shelton et al followed 172 patients (107 CD, 59 UC, and 6 unclassified IBD). Only 35.5\% of them were eligible for the GEMINI trials and $70.9 \%$ failed at least two anti-TNFs. In CD, $48.9 \%$ and 23.9\%; and in UC, $53.9 \%$ and $29.3 \%$ had clinical response and clinical remission at week 14, respectively. Adverse events occurred in $10.5 \%$ [29]. Vivio et al have recently demonstrated improvement in Harvey-Bradshaw Index and partial MAYO scores in $102 \mathrm{UC}$ and CD patients by week $14(\mathrm{P}<0.01,<0.001$ respectively), with $90 \%$ of patients maintaining therapy by week 14 . With respect to serious adverse events, 3 of the UC patients had undergone colectomy due to non-remitting disease, 5 of the CD patients had undergone CD-related surgeries and 2 other CD patients had severe infectious complications [32].

\section{Immunogenicity}

Of 620 vedolizumab-treated UC patients, 23 (3.7\%) had samples positive for anti-vedolizumab antibodies at any time, and $6(1.0 \%)$ had samples that were persistently positive through week 52. Concomitant immunosuppressives were associated with decreased immunogenicity. Of $814 \mathrm{CD}$ patients receiving vedolizumab, $33(4.1 \%)$ had at least one antibody positive sample. Unlike among UC patients, concomitant immunosuppressives decreased immunogenicity [33].

In conclusion, vedolizumab has been proven effective in moderate-to-severe UC and CD, including nonresponders to TNF antagonists. No clear difference in efficacy has been observed with 8- versus 4 -week interval between doses. Concurrent treatment with glucocorticoids or immunosuppressants or previous treatment with TNF antagonists did not affect the outcome. Rate of serious adverse events was similar to placebo.

\section{Etrolizumab}

Etrolizumab is an IgG1 humanized monoclonal antibody that binds the $\beta 7$ subunit of the $\alpha 4 \beta 7$ and the $\alpha E \beta 7$ integrin heterodimers in the intestine. The safety and pharmacology of etrolizumab were evaluated in a randomized phase 1 study in patients with moderate-to-severe UC [34]. In a subsequent phase 2 study, patients with moderate-to-severe active UC were 
treated SC with three monthly doses of $100 \mathrm{mg}$, a loading dose of $420 \mathrm{mg}$ and then $300 \mathrm{mg}$, or placebo. Clinical remission occurred at week 10 in $20.5 \%$ of patients in the etrolizumab $100 \mathrm{mg}$ group $(\mathrm{P}=0.004), 10.3 \%$ of patients in the etrolizumab $420 \mathrm{mg}$ loading dose group $(\mathrm{P}=0.048)$, and no patients in the placebo group. Data from the phase II study show that concomitant use of steroids and immunomodulators and anti-TNF-naïve status were significantly associated with higher remission rates, although no significant differences in mucosal healing rate (defined as MAYO score $=0$ ) were identified [35]. More studies are needed to confirm these data due to the small total sample size $(n=38$, 81 etrolizumab therapy patients in phase I and II studies) [36].

\section{Immunogenicity}

Of 81 patients in the phase II study, four (5\%) had detectable antidrug antibodies after treatment. Occurrence of adverse events did not seem to be associated with the presence of antidrug antibodies [35].

\section{Ustekinumab}

Ustekinumab is a human monoclonal immunoglobulin that targets P40, the shared subunit of the interleukins (IL)-12 and IL-23 [37]. It has been shown to be effective in psoriasis and psoriatic arthritis (PHOENIX and P-SUMMIT phase III trials respectively), and is now evaluated for its efficacy in CD [38]. In the phase IIb CERTIFI trial 526 CD patients who failed anti-TNFs were randomized to either ustekinumab or placebo. Clinical response at week 6 was achieved in $36.6 \%$, $34.1 \%$, and $39.7 \%$ of patients receiving an IV dose of 1,3 , or $6 \mathrm{mg} / \mathrm{kg}$, respectively, and in only $23.5 \%$ of those treated with placebo ( $\mathrm{P}=0.005$ for $6 \mathrm{mg} / \mathrm{kg}$ vs. placebo). Week 6 clinical remission was similar for the ustekinumab groups and placebo. $69.4 \%$ of ustekinumab maintenance therapy patients $(90 \mathrm{mg}$ SC at weeks 8 and 16) maintained their response at week 22, as compared to $42.5 \%$ in those randomized to receive placebo $(\mathrm{P}<0.05)$. Due to the small numbers of patients in the dose subgroups, the optimal dosage of ustekinumab is unclear. Fifty patients were evaluated for mucosal healing. In the placebo group, 1/9 reached mucosal healing, compared with $8 / 41(19.5 \%)$ of ustekinumab patients $(\mathrm{P}=1.00)[39,40]$.

In a real-life cohort of 38 severe $\mathrm{CD}$ patients who failed anti-TNFs, an initial clinical response to SC ustekinumab was observed in $73.7 \%$ of the patients. Dose escalation was needed in $47.7 \%$ and was successful in $61.1 \%$ of the patients [41]. The UNITI I phase 3 trial had confirmed the results of the CERTIFI among moderate-to-severe CD patients refractory to one or more anti-TNFs; IV ustekinumab was demonstrated to induce clinical response and remission and was well tolerated throughout induction. Clinical response at week 6 was observed in $33.7 \%$ of the $6 \mathrm{mg} / \mathrm{kg}$ and $34.3 \%$ of the $130 \mathrm{mg}$ groups versus $21.5 \%$ in the placebo group $(\mathrm{P}=0.003$ and 0.002 , respectively). Clinical remission $(\mathrm{CDAI}<150)$ at week 8 was observed in $20.9 \%$ of the $6 \mathrm{mg} / \mathrm{kg}$ ustekinumab group and $15.9 \%$ of the $130 \mathrm{mg}$ group versus $7.3 \%$ of placebo patients $(\mathrm{P}<0.001, \mathrm{P}=0.003$, respectively) In a recent retrospective study by Wils et al, 79 patients (65\%) improved within 3 months of starting ustekinumab. Concomitant immunomodulators increased the odds of clinical improvement (odds ratio, 5.43; $95 \%$ confidence interval, 1.14-25.77; $\mathrm{P}=0.03$ ). Over a median follow up of 9.8 months, the cumulative probabilities that patients maintained clinical benefit for 6 and 12 months after induction were $93 \%$ and $68 \%$, respectively [42].

In the induction phase of the CERTIFI trial, infection rates were also similar between ustekinumab and placebo patients. In the maintenance phase (approximately 25 weeks of follow up) neither deaths, nor serious opportunistic infections were identified. The long-term safety profile of ustekinumab has been evaluated in the treatment of psoriasis as well [43]. Pooling safety data from 4 clinical trials of ustekinumab for psoriasis, a total of 3117 patients were given at least one dose of ustekinumab. Serious adverse events rates at five years at year 5 were 7.0 and 7.2 per 100 patients years; serious infections rates were 0.98 and 1.19. No increase in adverse events, overall mortality or malignancies was identified, compared with an age-matched and sex-matched US population [40]. One case of demyelination in a patient receiving ustekinumab for $\mathrm{CD}$ has been recently reported [44]. Ongoing phase 3 clinical trials in $\mathrm{CD}$ are underway and the results are eagerly awaited. In recently presented results from the UNITI II, ustekinumab doses $6 \mathrm{mg} / \mathrm{kg}$ and $130 \mathrm{mg}$, showed significant improvement versus placebo in CDAI, C-reactive protein (CRP), and fecal calprotectin [45].

\section{Immunogenicity}

In the phase 2b CERTIFI trial, 427 ustekinumab-treated patients had available serum samples for analysis. Three $(0.7 \%)$ had positive antibodies to ustekinumab at week 36 . A recent publication on psoriasis showed that at weeks 16 and 28 serum levels of ustekinumab did not correlate with response status [46]. Nevertheless, a study on refractory CD patients, reported in an abstract form, stated that ustekinumab $>4.5 \mu \mathrm{g} / \mathrm{mL}$, compared to lower levels, increased endoscopic response $(81.3 \%$ vs. $25 \%, \mathrm{P}=0.008)$ and the combined outcome of steroid-free clinical remission and endoscopic response (50\% vs. $15 \%, \mathrm{P}=0.024$ ) [47].

In summary, ustekinumab is an antibody to a subunit of cytokines IL-12 and IL-23. It has been shown to induce clinical response in approximately $37 \%$ of CD patients who failed antiTNFs. Sustained response and mucosal healing have been equivocal, perhaps due to limited data so far.

\section{JAK kinase inhibitors}

\section{Tofacitinib}

Tofacitinib is an oral inhibitor of JAK 1, 2 and 3, expected to block signaling involving gamma-chain-containing cytokines including IL $-2,-4,-7,-9,-15$ and -21 . Tofacitinib has been recently approved for treatment of RA, and is under evaluation for both UC and CD. Tofacitinib has been demonstrated to be effective in patients with moderately-to-severely active 
UC [48]. A major phase II study by Sandborn et al enrolled 194 patients with moderately-to-severely active UC to oral tofacitinib $0.5 \mathrm{mg}, 3 \mathrm{mg}, 10 \mathrm{mg}, 15 \mathrm{mg}$, or placebo. Tofacitinib was administered for 8 weeks twice daily without concomitant immunomodulators or biologics. There was a dose-dependent effect with clinical response observed in $32 \%, 48 \%, 61 \%$, and $78 \%$ of patients treated with tofacitinib $0.5 \mathrm{mg}, 3 \mathrm{mg}, 10 \mathrm{mg}$, and $15 \mathrm{mg}$ doses, respectively, compared with $42 \%$ of patients under placebo $(\mathrm{P}<0.001 \mathrm{for} 15 \mathrm{mg})$. Clinical remission at week 8 was observed in $13 \%, 33 \%, 48 \%, 41 \%$ of patients treated with tofacitinib $0.5 \mathrm{mg}, 3 \mathrm{mg}, 10 \mathrm{mg}$, and $15 \mathrm{mg}$ doses $(\mathrm{P}=0.001$ for $10 \mathrm{mg}$ and $15 \mathrm{mg}$ ), respectively, compared with $10 \%$ under placebo. Endoscopic remission at 8 weeks occurred in 1 of 48 patients (2\%) receiving placebo, compared with 3 of $31(10 \%)$ receiving $10 \mathrm{mg}$ of tofacitinib $(\mathrm{P}<0.001)$, and 13 of $49(27 \%)$ receiving $15 \mathrm{mg}$ of tofacitinib $(\mathrm{P}<0.001)$. In the phase 2 randomized controlled trial of tofacitinib in CD, 139 patients with moderate-to-severe CD, who failed immunomodulators or biologics were randomized to tofacitinib $1 \mathrm{mg}, 5 \mathrm{mg}, 15 \mathrm{mg}$, or placebo twice daily for a total of 4 weeks. The primary endpoint of clinical response was achieved in $36 \%, 58 \%$, and $46 \%$ of patients in the $1 \mathrm{mg}, 5 \mathrm{mg}$, and $15 \mathrm{mg}$ tofacitinib arms respectively, which was not significantly different from the $47 \%$ response rate in the placebo group. Clinical remission rates were also similar among tofacitinib and placebo groups. Notwithstanding, inflammatory marker levels (CRP and fecal calprotectin) from baseline to week 4 were lower among tofacitinib patients (especially higher doses of 10 or $15 \mathrm{mg}$ ) [48].

The adverse effect profile for tofacitinib appears to be similar to other biologics, including bacterial, fungal, and viral infections and solid malignancies and lymphoma. Specifically, a large phase 3 RA study demonstrated higher rates of serious infections in the tofacitinib 5 and $10 \mathrm{mg}$ groups compared with placebo (6 vs. 0 events). In a study on kidney transplant patients [49], anemia, neutropenia and post-transplant lymphoproliferative disorder occurred more frequently in tofacitinib patients compared with cyclosporine [50]. In addition, in RA as well as UC and CD studies, a dose-dependent increase in both LDL and HDL cholesterol concentrations has been observed at 8 weeks with tofacitinib, which reversed after discontinuation [48].

\section{Immunogenicity}

To the best of our knowledge, immunogenicity of tofacitinib has not been studied so far. In conclusion, tofacitinib is an orally administered JAK inhibitor. In phase 2 trials, $15 \mathrm{mg}$ of tofacitinib showed significantly higher rates of clinical remission compared with placebo (approx. 40\%) in UC patients. With respect to $\mathrm{CD}$, no clear clinical benefit could be demonstrated.

\section{Concluding remarks}

Nowadays, biological therapy is considered the mainstay for moderate-to-severe UC and CD. The anti-TNFs infliximab and adalimumab have been extensively used and shown to induce clinical and endoscopic remission. Nevertheless, many do not respond initiallyor lose response. After certolizumab, golimumab is the fourth and last anti-TNF currently available for IBD. It has been shown to be effective for induction and maintenance of clinical and endoscopic remission in anti-TNF naive UC patients (approx. 50\% sustained remission). Vedolizumab is an anti-integrin, an integral part of the leukocyte adhesion and trafficking system in the gut. It has been proven effective in moderate-to-severe UC and CD (approx. 40\% sustained remission rates), including non-responders to TNF antagonists. Etrolizumab is another anti-integrin, currently studied at phase 3 trials for UC. Phase I and II studies demonstrated that with optimal dosing, remission rate is approximately $20 \%$. Data are lacking as to several key parameters such as mucosal healing rate and response in anti-TNF failure. Another new biologic is ustekinumab, an antibody to a subunit of IL-12 and IL-23. It has been shown to induce clinical response in approx. 37\% of CD patients who failed anti-TNFs. Finally, tofacitinib is an orally administered JAK inhibitor; $15 \mathrm{mg}$ of tofacitinib showed significantly higher rates of clinical remission as compared to placebo (approx. 40\%) in UC patients. Several other biologics are underway; PF-00547659, a monoclonal antibody against MAdCAM-1 and several orally administered biologics, including avaxia, an anti-TNF, vercirnon, an anti-CCR 9, and SMAD7, an antisense oligonucleotide which suppresses transforming growth factor $\beta 1$. Efficacy of these formulations for both CD and UC is currently being studied [24].

\section{References}

1. Ben-Horin S. Loss of response to anti-tumor necrosis factors: what is the next step? Dig Dis 2014;32:384-388.

2. Ungar B, Chowers Y, Yavzori M, et al. The temporal evolution of antidrug antibodies in patients with inflammatory bowel disease treated with infliximab. Gut 2014;63:1258-1264.

3. Magro F, Peyrin-Biroulet L, Sokol H, et al. Extra-intestinal malignancies in inflammatory bowel disease: results of the $3^{\text {rd }}$ ECCO Pathogenesis Scientific Workshop (III). J Crohns Colitis 2014;8:31-44.

4. Peyrin-Biroulet L, Khosrotehrani K, Carrat F, et al. Increased risk for nonmelanoma skin cancers in patients who receive thiopurines for inflammatory bowel disease. Gastroenterology 2011;141:16211628; e1-5.

5. Hanauer SB, Feagan BG, Lichtenstein GR, et al. Maintenance infliximab for Crohn's disease: the ACCENT I randomised trial. Lancet 2002;359:1541-1549.

6. Sands BE, Anderson FH, Bernstein $\mathrm{CN}$, et al. Infliximab maintenance therapy for fistulizing Crohn's disease. $N$ Engl J Med 2004;350:876-885.

7. Rutgeerts P, Sandborn WJ, Feagan BG, et al. Infliximab for induction and maintenance therapy for ulcerative colitis. $N$ Engl J Med 2005;353:2462-2476.

8. Colombel JF, Sandborn WJ, Rutgeerts P, et al. Adalimumab for maintenance of clinical response and remission in patients with Crohn's disease: the CHARM trial. Gastroenterology 2007;132:52-65.

9. Sandborn WJ, van Assche G, Reinisch W, et al. Adalimumab induces and maintains clinical remission in patients with moderate-tosevere ulcerative colitis. Gastroenterology 2012;142:257-265; e1-3.

10. Stein AC, Rubin DT, Hanauer SB, et al. Incidence and predictors 
of clinical response, re-induction dose, and maintenance dose escalation with certolizumab pegol in Crohn's disease. Inflamm Bowel Dis 2014;20:1722-1728.

11. Schreiber S, Rutgeerts P, Fedorak RN, et al. A randomized, placebocontrolled trial of certolizumab pegol (CDP870) for treatment of Crohn's disease. Gastroenterology 2005;129:807-818.

12. Sandborn WJ, Feagan BG, Stoinov S, et al. Certolizumab pegol for the treatment of Crohn's disease. N Engl J Med 2007;357:228-238.

13. Schreiber S, Khaliq-Kareemi M, Lawrance IC, et al. Maintenance therapy with certolizumab pegol for Crohn's disease. N Engl J Med 2007;357:239-250.

14. Lowenberg $M$, de Boer N, Hoentjen F. Golimumab for the treatment of ulcerative colitis. Clin Exp Gastroenterol 2014;7:53-59.

15. Sandborn WJ, Feagan BG, Marano C, et al. Subcutaneous golimumab induces clinical response and remission in patients with moderate-to-severe ulcerative colitis. Gastroenterology 2014;146:85-95; quiz e14-e15.

16. Sandborn WJ, Feagan BG, Marano C, et al. Subcutaneous golimumab maintains clinical response in patients with moderateto-severe ulcerative colitis. Gastroenterology 2014;146:96-109; e1.

17. Rutgeerts P, Feagan BG, Marano CW, et al. Randomised clinical trial: a placebo-controlled study of intravenous golimumab induction therapy for ulcerative colitis. Aliment Pharmacol Ther 2015;42:504-514.

18. Cote-Daigneault J, Bouin $M$, Lahaie $R$, et al. Biologics in inflammatory bowel disease: what are the data? United European Gastroenterol J 2015;3:419-428.

19. Chen DY, Chen YM, Hung WT, et al. Immunogenicity, drug trough levels and therapeutic response in patients with rheumatoid arthritis or ankylosing spondylitis after 24-week golimumab treatment. Ann Rheum Dis 2015;74:2261-2264.

20. $\mathrm{Xu} \mathrm{ZH,} \mathrm{Lee} \mathrm{H}, \mathrm{Vu} \mathrm{T}$, et al. Population pharmacokinetics of golimumab in patients with ankylosing spondylitis: impact of body weight and immunogenicity. Int J Clin Pharmacol Ther 2010;48:596-607.

21. Akiho H, Yokoyama A, Abe S, et al. Promising biological therapies for ulcerative colitis: A review of the literature. World J Gastrointest Pathophysiol 2015;6:219-227.

22. Sandborn WJ, Colombel JF, Enns R, et al. Natalizumab induction and maintenance therapy for Crohn's disease. N Engl J Med 2005;353:1912-1925.

23. Bloomgren G, Richman S, Hotermans C, et al. Risk of natalizumabassociated progressive multifocal leukoencephalopathy. $N$ Engl $J$ Med 2012;366:1870-1880.

24. Lowenberg M, D’Haens G. Next-generation therapeutics for IBD. Curr Gastroenterol Rep 2015;17:21.

25. Feagan GSC, Melmed GY, Isaacs K, et al. Efficacy of vedolizumab maintenance therapy with and without continued immunosuppressant use in GEMINI 1 and GEMINI 2. 2015.

26. Feagan BG, Rutgeerts P, Sands BE, et al. Vedolizumab as induction and maintenance therapy for ulcerative colitis. $N$ Engl $J$ Med 2013;369:699-710.

27. Danese S, Fiorino G, Peyrin-Biroulet L, et al. Biological agents for moderately to severely active ulcerative colitis: a systematic review and network meta-analysis. Ann Intern Med 2014;160:704-711.

28. Cherry LN, Yunker NS, Lambert ER, et al. Vedolizumab: an alpha4beta7 integrin antagonist for ulcerative colitis and Crohn's disease. Ther Adv Chronic Dis 2015;6:224-233.

29. Shelton E, Allegretti JR, Stevens B, et al. Efficacy of vedolizumab as induction therapy in refractory IBD patients: a multicenter cohort. Inflamm Bowel Dis 2015;21:2879-2885.

30. Luthra P, Peyrin-Biroulet L, Ford AC. Systematic review and meta-analysis: opportunistic infections and malignancies during treatment with anti-integrin antibodies in inflammatory bowel disease. Aliment Pharmacol Ther 2015;41:1227-1236.
31. Chandar AK, Singh S, Murad MH, et al. Efficacy and safety of natalizumab and vedolizumab for the management of Crohn's disease: a systematic review and meta-analysis. Inflamm Bowel Dis 2015;21:1695-708.

32. Vivio EE, Kanuri N, Gilbertsen JJ, et al. Vedolizumab effectiveness and safety over the first year of use in an IBD clinical practice. J Crohns Colitis 2015. [Epub ahead of print]

33. Sandborn WJ, Feagan BG, Rutgeerts P, et al. Vedolizumab as induction and maintenance therapy for Crohn's disease. $N$ Engl J Med 2013;369:711-721.

34. Rutgeerts PJ, Fedorak RN, Hommes DW, et al. A randomised phase I study of etrolizumab (rhuMAb beta7) in moderate to severe ulcerative colitis. Gut 2013;62:1122-1130.

35. Vermeire S, O'Byrne S, Keir M, et al. Etrolizumab as induction therapy for ulcerative colitis: a randomised, controlled, phase 2 trial. Lancet 2014;384:309-318.

36. Fiorino G, Danese S. Etrolizumab in ulcerative colitis: tightening leukocyte traffic control in the inflamed mucosa. Gastroenterology 2014;147:1433-1435.

37. Lodyga M, Eder P, Bartnik W, et al. New pharmaceuticals in inflammatory bowel disease. Prz Gastroenterol 2015;10:57-60.

38. Toussirot E, Michel F, Bereau M, et al. Ustekinumab in chronic immune-mediated diseases: a review of long term safety and patient improvement. Patient Prefer Adherence 2013;7:369-377.

39. Sandborn WJ, Gasink C, Gao LL, et al. Ustekinumab induction and maintenance therapy in refractory Crohn's disease. $N$ Engl J Med 2012;367:1519-1528.

40. Leung Y, Panaccione R. Update on ustekinumab for the treatment of Crohn's disease. Gastroenterol Clin North Am 2014;43:619-630.

41. Kopylov U, Afif W, Cohen A, et al. Subcutaneous ustekinumab for the treatment of anti-TNF resistant Crohn's disease--the McGill experience. J Crohns Colitis 2014;8:1516-1522.

42. Wils P, Bouhnik Y, Michetti P, et al. Subcutaneous ustekinumab provides clinical benefit for two-thirds of patients with Crohn's disease refractory to anti-tumor necrosis factor agents. Clin Gastroenterol Hepatol 2016;14:242-250.

43. Papp KA, Griffiths CE, Gordon K, et al. Long-term safety of ustekinumab in patients with moderate-to-severe psoriasis: final results from 5 years of follow-up. Br J Dermatol 2013;168:844-854.

44. Badat Y, Meissner WG, Laharie D. Demyelination in a patient receiving ustekinumab for refractory Crohn's disease. J Crohns Colitis 2014;8:1138-1139.

45. Feagan B, Siegel CA, Melmed G. A Multicenter, randomized, double-blind, placebo-controlled phase 3 study of ustekinumab, a human monoclonal antibody to IL-12/23P40, in patients with moderately- to severely-active Crohn's disease who are naïve or not refractory to anti-TNFa: results from the UNITI-2 study. United European Gastroenterology Week, Barcelona Spain, 2015.

46. Menting SP, van den Reek JM, Baerveldt EM, et al. The correlation of clinical efficacy, serum trough levels and antidrug antibodies in ustekinumab-treated patients with psoriasis in a clinical-practice setting. Br J Dermatol 2015;173:855-857.

47. Battat R, Bessissow T. Association of ustekinumab trough concentrations with clinical, biochemical and endoscopic outcomes. ECCO 2016. Amsterdam, Netherlands, 2016.

48. Sandborn WJ, Ghosh S, Panes J, et al. Tofacitinib, an oral Janus kinase inhibitor, in active ulcerative colitis. $N$ Engl $J$ Med 2012;367:616-624.

49. Fleischmann R, Kremer J, Cush J, et al. Placebo-controlled trial of tofacitinib monotherapy in rheumatoid arthritis. $N$ Engl J Med 2012;367:495-507.

50. Vincenti F, Tedesco Silva H, Busque S, et al. Randomized phase $2 \mathrm{~b}$ trial of tofacitinib $(\mathrm{CP}-690,550)$ in de novo kidney transplant patients: efficacy, renal function and safety at 1 year. Am J Transplant 2012;12:2446-2456. 